\title{
Novel Controllable Semiactive Devices for Reshaping Structural Response
}

\author{
XiaoQi Chen, Senior Member, IEEE, J. Geoffrey Chase, Kerry J. Mulligan, Geoffrey W. Rodgers, and John B. Mander
}

\begin{abstract}
Semiactive dampers and actuators hold significant promise for their ability to add supplemental damping and reduce structural response, particularly under earthquake loading. Novel controllable devices utilizing off the shelf components and control systems have been developed to modify structural response. The devices are presented from design, modeling, analysis, and validation via hybrid testing and experimental shake table results. All cases are compared with independent analytical predictions based on first principles analysis.
\end{abstract}

Index Terms-Device dynamics, hybrid test, semiactive devices, structural response.

\section{INTRODUCTION}

$\mathbf{S}$ EMIACTIVE control is emerging as an effective method of mitigating structural damage from large environmental loads, with two main benefits over active control and passive solutions. First, a large power/energy supply is not required to have a significant impact on response. Second, they provide the broad range of control that a tuned passive system cannot, making them better able to respond to changes in structural behavior due to nonlinearity, damage, or degradation over time. Semiactive systems are also strictly dissipative and do not add energy to the system, guaranteeing stability.

Semiactive devices are particularly suitable in situations where the device may not be required to be active for extended periods of time, but may be suddenly required to produce large forces [1]. The potential of semiactive devices and control methods to mitigate damage during seismic events is well documented [2]-[4]. However, most structural control researches, both active and semiactive, have been analytical with very little full-scale testing. Adaptive vibration isolation for axially moving beams was discussed in [5]. The work introduces an active pivoting roller that adaptively decouples adjacent spans, thereby isolating a controlled span from bounded disturbances in an adjacent span. A recursive experimental design method for simul-

Manuscript received February 10, 2008; revised May 13, 2008. Current version published December 17, 2008. Recommended by Technical Editor Z. Lin. This work was supported in part by the New Zealand Earthquake Research Commission (EQC) Research Foundation and in part by the New Zealand Tertiary Education Commission (TEC) Top Achiever Scholarships.

X. Chen, J. G. Chase, K. J. Mulligan, and G. W. Rodgers are with the Department of Mechanical Engineering, University of Canterbury, Christchurch 8140, New Zealand (e-mail: xiaoqi.chen@canterbury.ac.nz; geoff.chase@canterbury. ac.nz; kerry.mullingan@ canterbury.ac.nz; gwr37@student.canterbury.ac.nz).

J. B. Mander is with the Department of Civil Engineering, Texas A\&M University, College Station, TX 77843-3136 USA (e-mail: jmander@ civil.tamu.edu).

Color versions of one or more of the figures in this paper are available online at http://ieeexplore.ieee.org.

Digital Object Identifier 10.1109/TMECH.2008.2003958 taneously optimizing both mechanical structure and control is presented in [6]. Control gains are optimally tuned for a given prototype of mechatronic system, and its mechanical structure is physically modified, so that control performance can be further improved. The mechanical structure is modified recursively and quickly by using structure reinforcement and rapid prototyping techniques. However, it would be more significant that structure response can be reshaped and reduced using mechatronic device without modifying the structure.

Ideally, semiactive devices should be reliable and simple. Resetable devices fit these criteria as they can be constructed with ease and utilize well-understood fluids, such as air. These attributes contrast with more complicated semiactive devices such as electrorheological and magnetorheological devices to resist motion [7], [8]. Instead of altering the damping of the system, resetable devices nonlinearly alter the stiffness with the stored energy being released as the compressed fluid is allowed to revert to its initial pressure.

Prior to this research, the largest capacity test device was approximately $100 \mathrm{~N}$, and it offered the capability of releasing all the stored energy effectively instantaneously relative to the structural periods being considered [9]. For larger devices, the rate of energy dissipation may be more important as the flow rates required for large systems to release large amounts of stored energy will potentially be very high. Hence, resetable device design and implementation, while offering significant promise, are still in their infancy.

Semiactive damping via resetable devices also offers the opportunity to sculpt or reshape the resulting structural hysteresis loop to meet design needs, as enabled by the ability to actively control the device valve and reset times. For example, given a sinusoidal response, a typical viscously damped, linear structure has the hysteresis loop definitions schematically shown in Fig. 1(a), where the linear force deflection response is added to the circular force-deflection response due to viscous damping to create the well-known overall hysteresis loop. Fig. 1(b) shows the same behavior for a simple resetable device where all stored energy is released at the peak of each sine wave cycle and all other motion is resisted [9]. This form is denoted as " $1-4$ device," as it provides damping in all four quadrants. A stiff damper will dissipate significant energy. However, the resulting base-shear force is increased. If the control law is changed such that only motion toward the zero position (from the peak values) is resisted, the force-deflection curves that result are shown in Fig. 1(d). In this case, the semiactive resetable damper force reduces base-shear demand by providing damping forces only in quadrants 2 and 4; a "2-4 device." Fig. 1(c) shows a damper that resists motion only away from equilibrium and increases base 

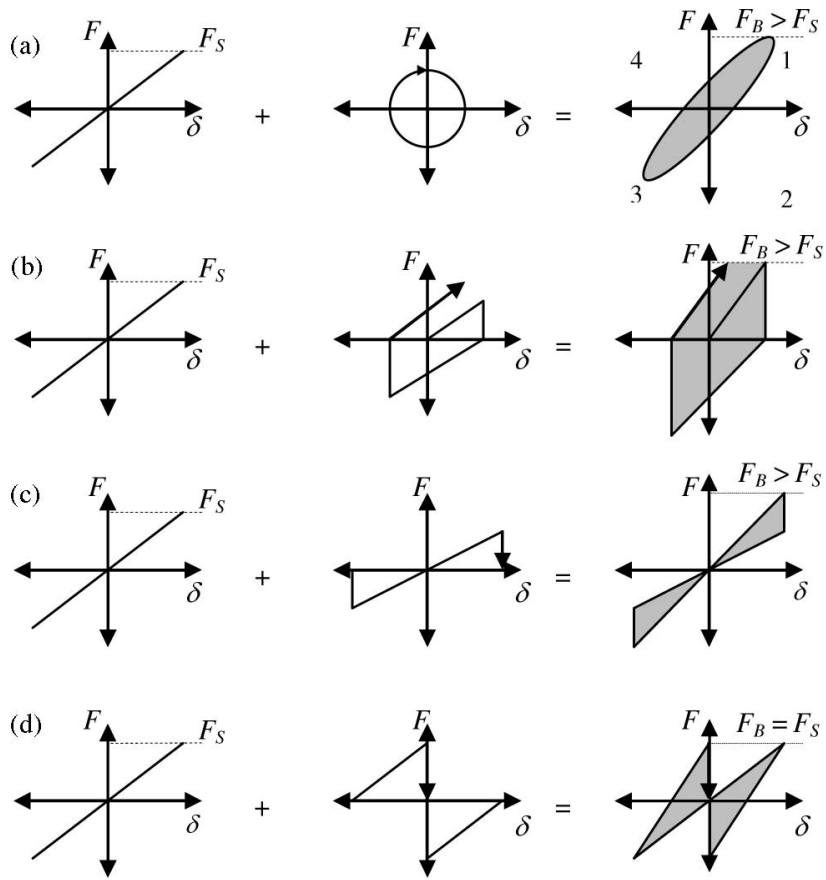

Fig. 1. Schematic hysteresis for (a) viscous damping, (b) a 1-4 device, (c) a 1-3 device, and (d) a 2-4 device. FB = total base shear, FS = base shear for a linear, undamped structure. FB $>$ FS indicates an increase due to the additional damping.

shear, a "1-3 device." As a result, the use of controllable semiactive devices offers the opportunity to reshape and customise the overall structural hysteretic behavior while providing supplemental damping [10].

Valve and device control for a 2-4 controlled resetable device are shown in Fig. 22 in the Appendix. This figure clearly delineates the control steps required to achieve the 2-4 device hysteresis loop in Fig. 1(d). The real-time control actions are also clearly stated in full.

This paper investigates the design, testing, and analysis of a one-fifth scale resetable device using air as the working fluid. The device is modeled and experimentally validated in several tests. The impact and efficacy of different control laws is determined, particularly with respect to reducing the demand on a structure during seismic events is investigated.

\section{DeVICE DyNAMICS, Model, AND DESIGN}

Semiactive devices are hydraulic spring elements with a resetable unstretched spring length, and therefore, add a nonlinear stiffness to the structure without altering the damping. Piston displacement stores energy by compressing the working fluid, with peak energy storage occurring at the peak displacement position. At this point, the stored energy can be released by discharging the fluid/air to the nonworking side of the device, thus resetting the unstretched spring length, as seen in Fig. 2(a), yielding the 1-4 device behavior of Fig. 1(b).

Fig. 2(b) shows a modified device design that treats each chamber independently [11], [12]. It eliminates the need to rapidly dissipate energy between the two chambers. The resulting independent control of the pressure and energy dissipation
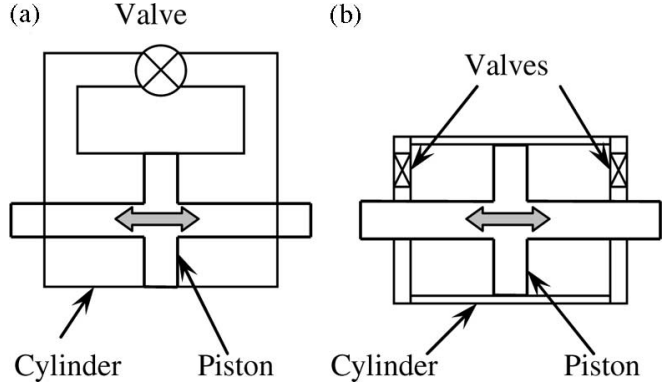

Fig. 2. Semiactive device schematics. (a) Conventional design with single valve and external plumbing system. (b) Independent chamber design where each valve vents to atmosphere for a pneumatic device.

on each side of the piston for each portion of response motion allows greater flexibility in designing the overall device behavior. This design thus enables a much broader range of control laws as each valve can be operated independently.

By utilizing air, analyzes and modeling of the device is made simpler [12]. Furthermore, utilizing air, the atmosphere is the fluid reservoir, eliminating the need for complex plumbing systems. These factors are added advantages over more complex semiactive electro- or magnetorheological dampers [7], [8].

Independent valves allow more time for pressures to equalize during the valve reset. While one chamber is under compression, the previously reset chamber can have the valve open to allow the pressure to equalize, as this does not affect the compression in the working chamber. This approach would not be feasible in the design of Fig. 2(a), as extending the valve reset time prevents the other chamber from storing energy.

Each chamber volume can be directly related to the piston displacement. Opening the valve of the compressed chamber dissipates the stored energy. If the working fluid behaves as an ideal gas, then the ideal gas law can be utilized [1], [9].

$$
p V^{\gamma}=c
$$

where $\gamma$ is the ratio of specific heats, $c$ is a constant, and $p$ and $V$ are, respectively, the pressure and volume in a chamber of the device. Assuming that the piston is centered and the initial chamber pressures are $P_{0}$ with initial volumes, $V_{0}$, the resisting force is a function of displacement, $x$ :

$$
\begin{aligned}
F(x) & =\left(p_{2}-p_{1}\right) A c \\
& =\left[\left(V_{0}+A x\right)^{-\gamma}-\left(V_{0}-A x\right)^{-\gamma}\right] A c .
\end{aligned}
$$

For small motions, (2) can be linearized

$$
F(x)=\frac{2 A^{2} \gamma P_{0}}{V_{0}} x
$$

where $A$ is the piston area. The effective stiffness of the resetable device is therefore defined:

$$
k_{1}=\frac{2 A^{2} \gamma P_{0}}{V_{0}}
$$

Similar equations can be used to independently model the pressure-volume status of each chamber of the device in 


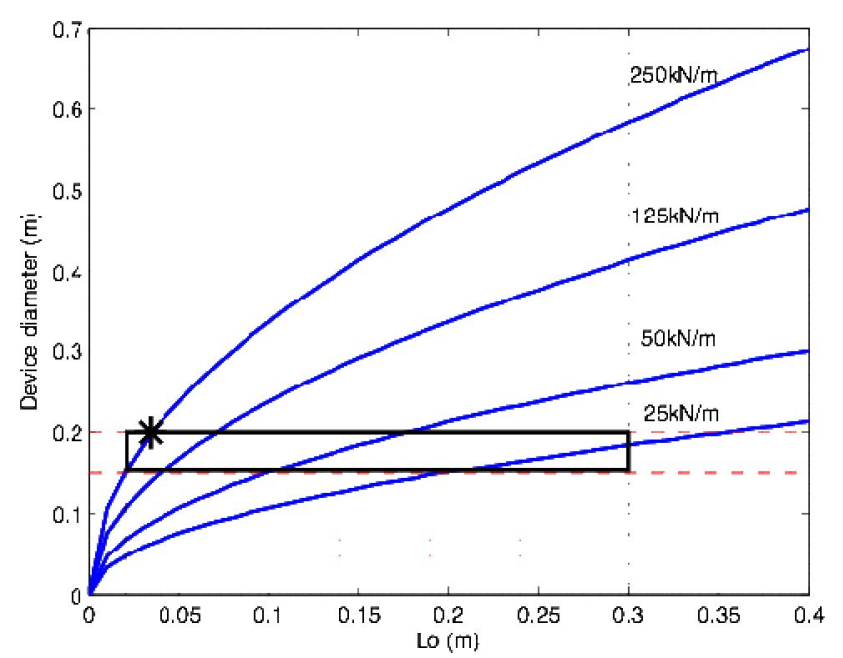

Fig. 3. Tradeoff curve relating device dimensions and stiffness. “*” = designed device $K=250 \mathrm{kN} / \mathrm{m}$.

Fig. 2(b). Equation (4) can then be used to design a device to produce set resisting forces for specified displacements, or set added stiffnesses, by parameterizing the design space [11], [12].

The device is designed for a one-fifth scale, four-story steel moment resisting frame with basic dimensions of $2.1 \times 1.2 \times 2.1$ $\mathrm{m}$ and a total seismic weight of $35.3 \mathrm{kN}$, as described by [13]. The natural period of the structure is $0.6 \mathrm{~s}$, typical of a fourstory reinforced concrete building. Given that the total actuator authority has a reasonable value of approximately 15\% [2], [14], and assuming that two actuators in the structure a stiffness value of $250 \mathrm{kN} / \mathrm{m}$ was required. This stiffness results in a force of $2.5 \mathrm{kN}$ developed at $10 \mathrm{~mm}$ displacement of the piston from its center position.

Tradeoff curves for a resetable actuator with air as the working fluid show the relationships between parameters. The primary parameters are the diameter, chamber length, and maximum piston displacement and are shown in Fig. 3.

These parameters control the stiffness of the device using (2)-(4). The design space (highlighted) is determined by combining these curves with practical, safety, and ease of handling constraints. These added constraints include ensuring the length of each chamber is superior to the maximum displacement of the piston, limiting the internal pressure to $2.5 \mathrm{~atm}$, keeping the weight of the device under $20 \mathrm{~kg}$ and the diameter under $0.2 \mathrm{~m}$.

An exploded view of the device is shown in Fig. 4. The piston head has four seals each located in a groove that ensure minimum air movement between the two chambers. The end caps are press fitted into the cylinder and held in place by four rods. An O-ring located between the end caps and the cylinder further ensures no leakage of air. Air is prohibited from escaping where the piston rod passes through the end caps by two seals located in the end caps. An elevation view is shown in Fig. 5, and the assembled prototype is shown attached to a hydraulic test system in Fig. 6.

The dimensions of the prototype device presented in Fig. 5 develop peak forces of approximately $20 \mathrm{kN}$ depending on stroke length and control law. It is important to note that for ease of

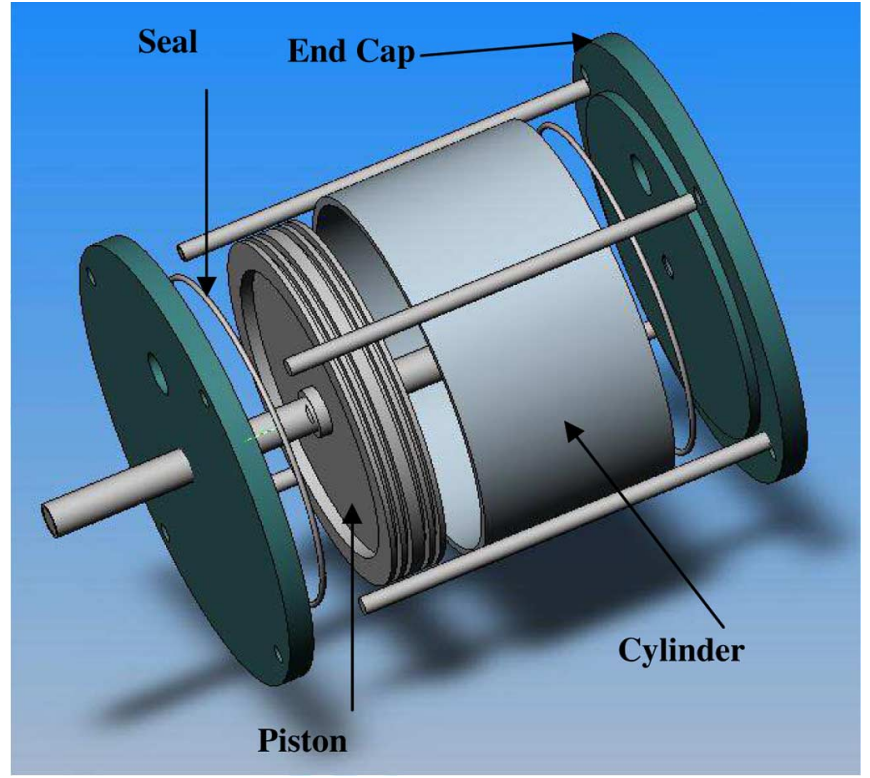

Fig. 4. Exploded view of prototype indication components.

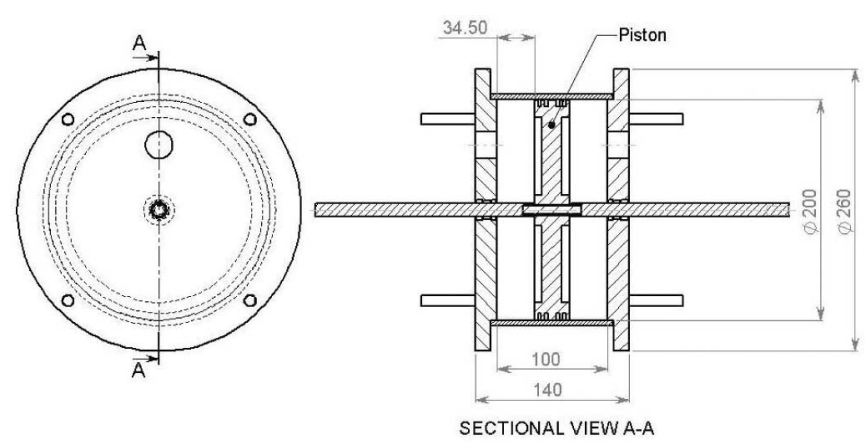

Fig. 5. Elevation view and basic dimensions.

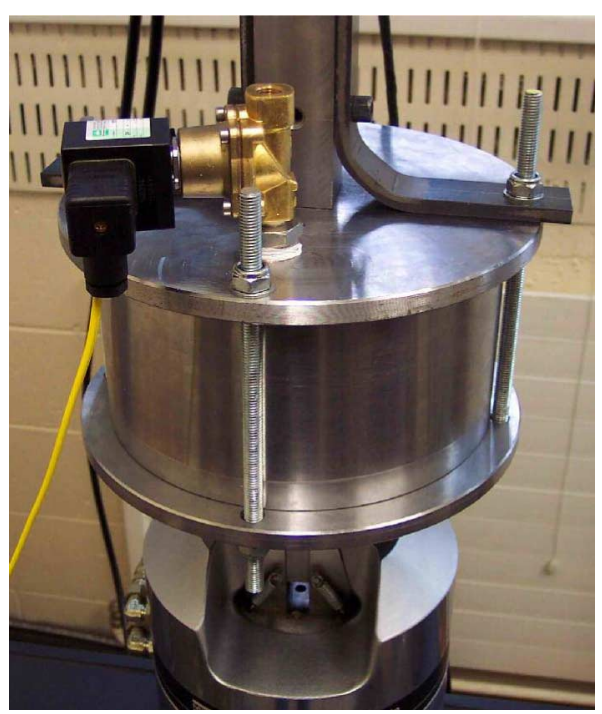

Fig. 6. Prototype device in test rig. 
implementation, the prototype is a pneumatic device, and a fullscale pneumatic device could easily produce resistive forces in the range of $100 \mathrm{kN} \mathrm{[10]-[12].} \mathrm{These} \mathrm{tradeoffs} \mathrm{in} \mathrm{design} \mathrm{and}$ device size are clearly shown in Fig. 3. The same approach can be extended to more viscous working fluids with much larger (up to $10 \times$ ) bulk modulus values, thus delivering much higher resistive forces up to $1 \mathrm{MN}$ or more, in a similar, relatively small package [12].

The device itself has two valves and a sensor (not shown in Fig. 6) for measuring shaft displacement. The solenoid valves have two states: open (active) and closed (default, no voltage). Hence, the closed state of the valves provides an air-based spring and a "fail safe" form of operation for the device. The sensor is a standard capacitive extensometer with accuracy to $0.05 \mathrm{~mm}$ of displacement.

The overall system is monitored and controlled using a dSpace real-time control prototyping system. This system is set to sample data from the sensor, as well as from force transducers in test equipment (as shown in Fig. 6) at a rate of $1 \mathrm{kHz}$. The overall system then runs the valves for sinusoidal or hybrid (hardware-in-loop) testing, where the latter case is characterized by a modeled structure using the physical device under seismic loads.

Initial model validation testing is performed using controlled sinusoidal inputs from the hydraulic test rig shown in Fig. 6. These inputs are varied in amplitude of displacement to test the force-displacement response of the structures. They are varied in frequency to determine the changes that arise with frequency, which are primarily related to the device's capability to release pressurized air via the relatively narrow valves. In this latter case, the use of independently controlled chambers provides a longer air release period, allowing greater energy dissipation than earlier one to four device designs [1], thus returning less force to the structural response.

\section{Model And Device Validation Tests}

Initial uncontrolled tests with a sine wave input for the piston displacement indicate that the device behaves as expected. The peak force developed at a displacement of $10 \mathrm{~mm}$ from the center ranges between 1.85 and $2.36 \mathrm{kN}$, as shown in Fig. 7, resulting in a stiffness between 185 and $236 \mathrm{kN} / \mathrm{m}$, respectively, depending on the frequency of the input signal. Higher frequencies produce a higher peak force. Reductions in from the design value are attributed to air loss via valve flexibility. Some of the force generated can be attributed to friction between the seals around the piston and the cylinder wall. This contribution is approximately $250 \mathrm{~N}$ as seen in Fig. 8, which shows the forcedisplacement plot for the device with both valves open and a sine wave input of $10 \mathrm{~mm}$ at $1 \mathrm{~Hz}$ and $3 \mathrm{~Hz}$. The curved portions of the plot are attributed to Coulomb damping as the air is forced through the open valves, which act as an orifice. The faster the air is forced through the restriction, the greater the resistance force, as seen in Fig. 8, where the $3 \mathrm{~Hz}$ plot reaches a higher force. Coulomb damping is not observed during controlled tests; however, the effect of forcing air through the valve is observed

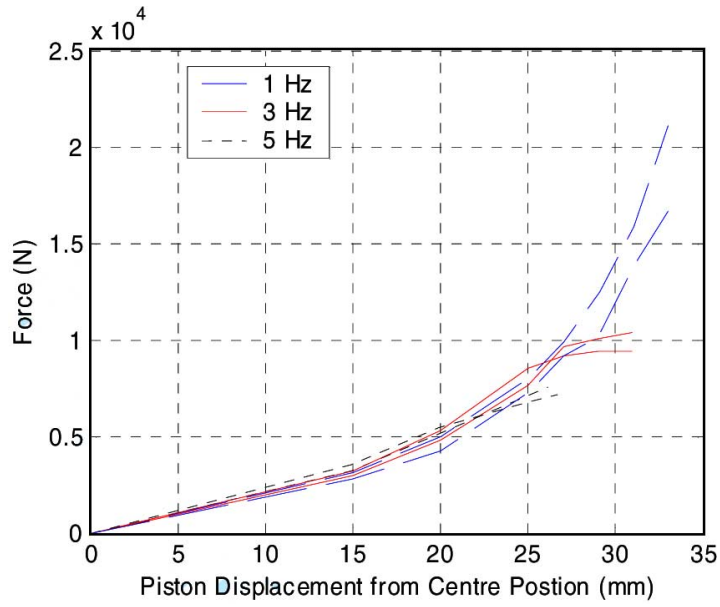

Fig. 7. Peak force vs. displacement at various input frequencies.

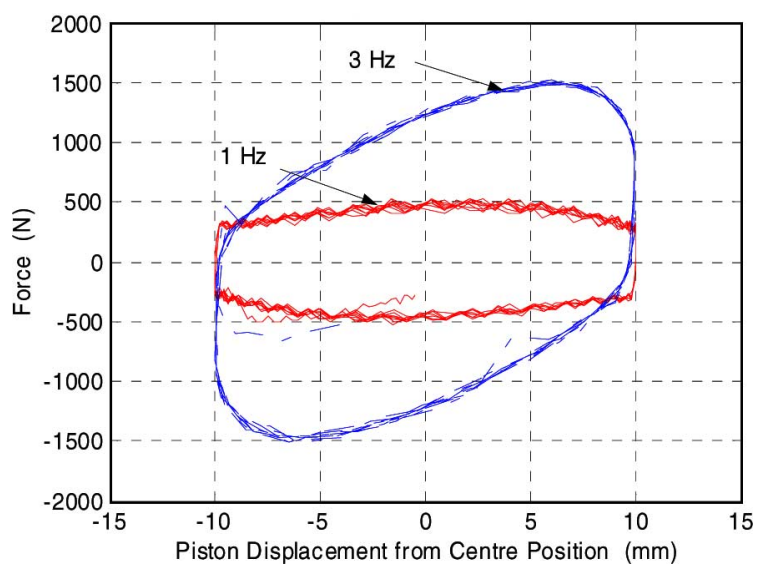

Fig. 8. Force vs. displacement with both valves open, indicates force due to friction between the seals and cylinder.

in the significant energy release times required relative to the input motion.

The force-displacement curves for different control laws, frequencies, and amplitudes of the input signal are shown in Figs. 9 and 10. Deviations from the "ideal" behavior occur due to energy release times that are not instantaneous, as well as friction between the seals and the cylinder wall. Fig. 9 shows the difference between holding the valves open for different lengths of time. The valve is opened at the maximum displacement and closed either $15 \mathrm{~mm}$ from the center (i.e., $5 \mathrm{~mm}$ from the peak position) or at the center position. The latter case results in a greater stiffness and hence a higher peak load. More specifically, the air column when the valve is closed is shorter, allowing the pressure to build up more quickly. This result suggests that the valves should be open at all times, except during the point from the centerline position to the maximum displacement for each side, which is counterintuitive and requires further investigation.

Fig. 10 shows the limits of the currently installed valves. The peak force at $1 \mathrm{~Hz}$ is lower than that for $0.5 \mathrm{~Hz}$, suggesting that the energy release time is insufficient to release all stored energy before the piston begins moving back in the same direction. For 


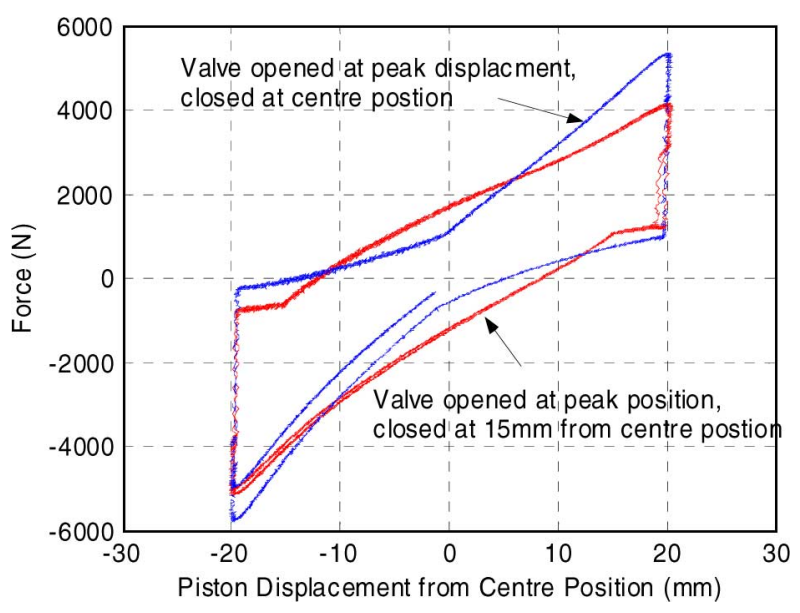

Fig. 9. Load vs. displacement for different control laws for a $0.1 \mathrm{~Hz} 20 \mathrm{~mm}$ displacement signal.

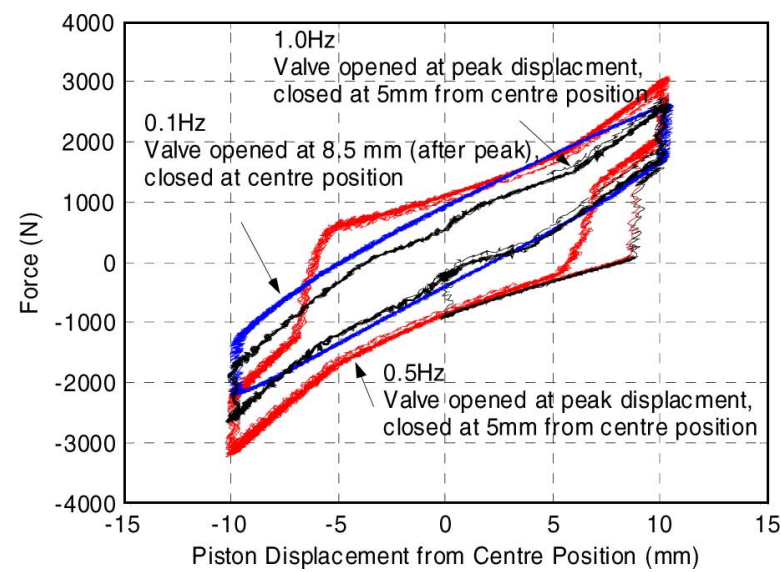

Fig. 10. Force vs. displacement for a $10 \mathrm{~mm}$ displacement signal at various frequencies and two control laws.

higher frequencies, larger or an increased number of valves will be needed to release the air in a timely fashion.

The flow rate out of the device is approximately $29 \mathrm{~L} / \mathrm{s}$, as shown in Fig. 11, as measured via the time for the force to return to zero after ramping displacement to a set value and relating force and volume using (3). These release times are now significant relative to the potential seismic input frequencies and motions, versus smaller prior devices.

Once the operating parameters of the device are understood, it was modeled in a single degree of freedom structure to investigate the accuracy of the analytical model and the impact of different control laws. Verification and hybrid testing [15] involves the following steps.

1) Sine waves with various amplitudes and frequencies are used as the ground motion.

2) A simulation is completed and the displacement of the structure and force provided by the "virtual" actuator recorded, as seen in Fig. 12(a).

3) This displacement is then input as the piston displacement and the force provided by the prototype device recorded [see Fig. 12(b)] and compared to the calculated force.

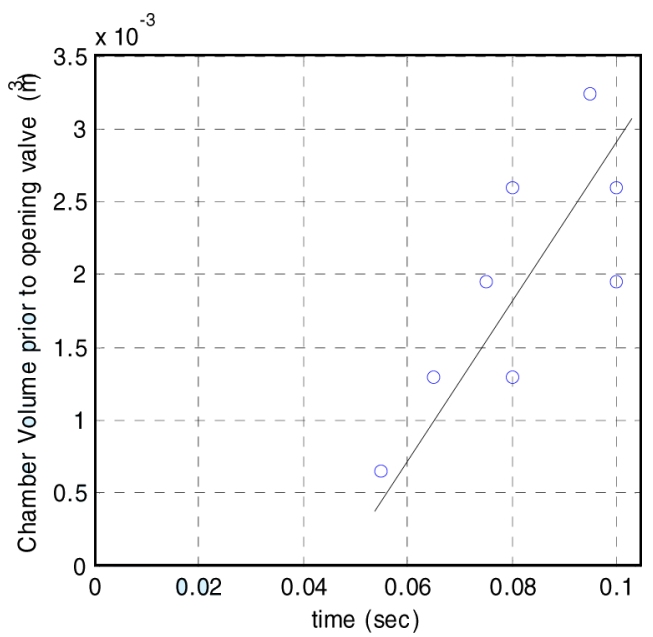

Fig. 11. Time to release energy from device depends on chamber volume prior to release. Circles show measured data.

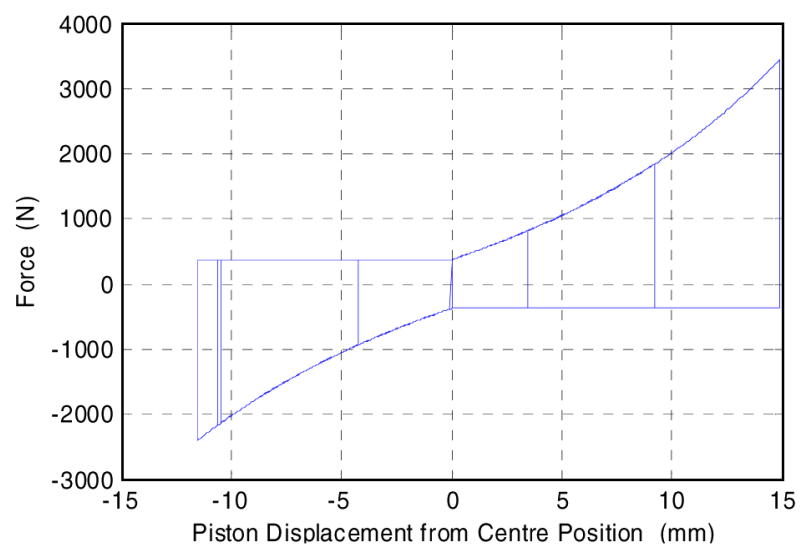

(a)

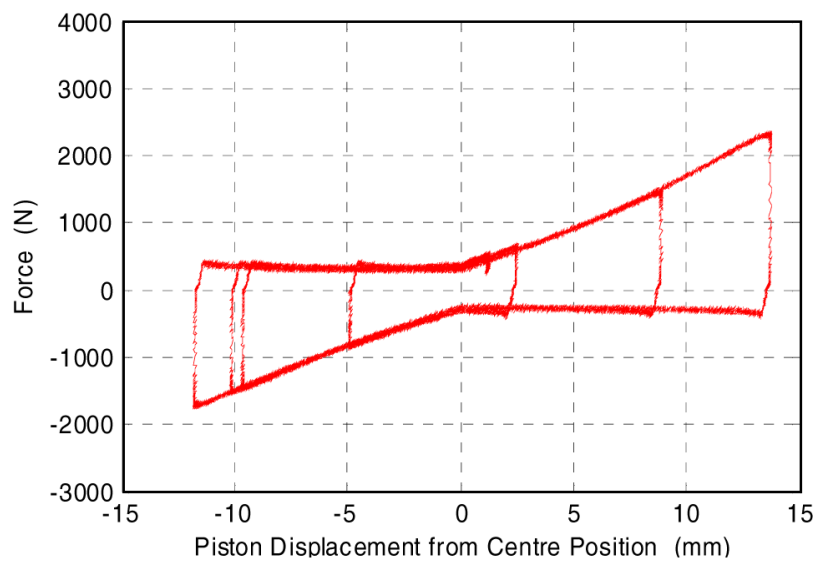

(b)

Fig. 12. Force-displacement curve for actuator in a single degree of freedom structure. Ground motion is a $2 \mathrm{~m} \cdot \mathrm{s}^{-2}$ sine wave of frequency $0.1 \mathrm{~Hz}$. (a) Analytical model prediction. (b) Experimental result.

This approach allows simple full-scale testing of the device with a virtual structure. It is therefore an iterative form of hybrid testing, enabled by the device's repeatability. The model is seen in Figs. 12 and 13 to be a good representation of the device.

Investigation of different control laws suggests that the forcedisplacement curve of the device and hence the structure can be 


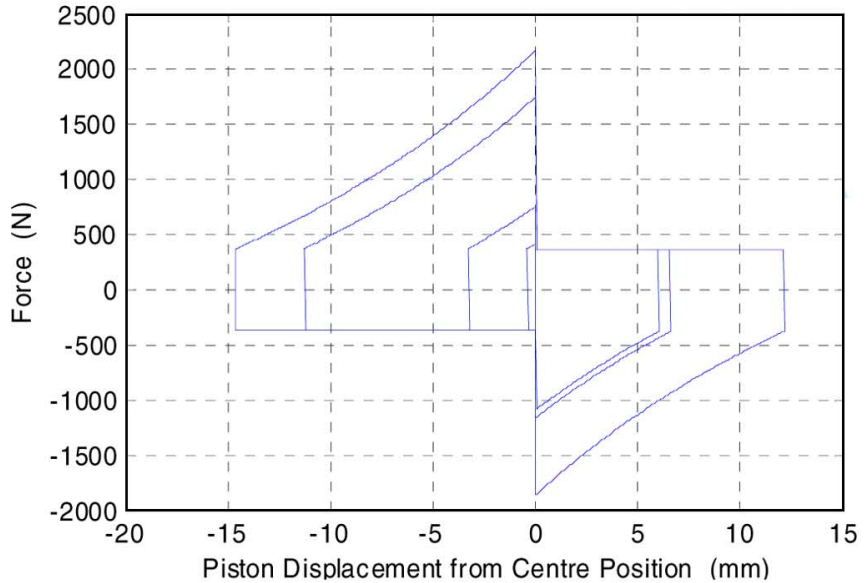

(a)

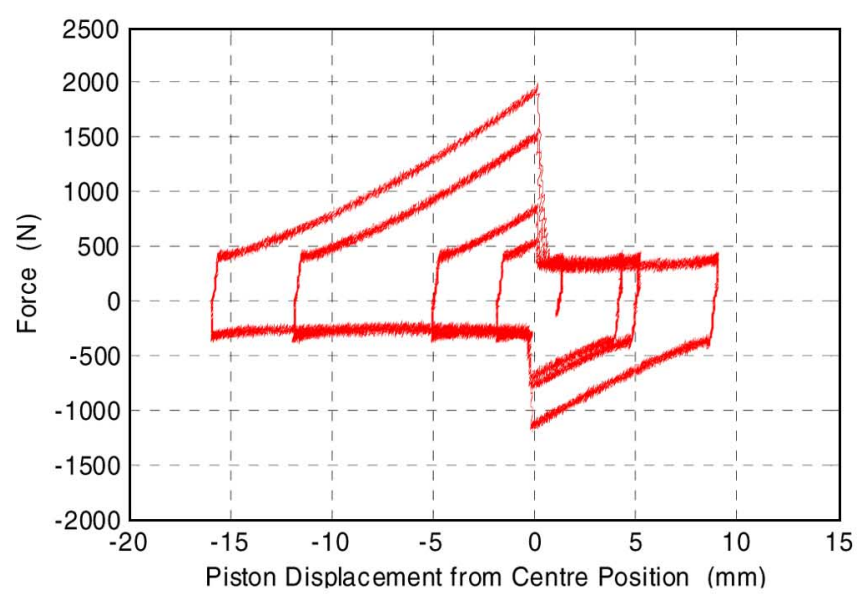

(b)

Fig. 13. Force-displacement curve for actuator in a single degree of freedom structure with $2-4$ control law. Ground motion is a $2 \mathrm{~m} \cdot \mathrm{s}^{-2}$ sine wave of frequency $0.1 \mathrm{~Hz}$. (a) Analytical model prediction. (b) Experimental result.

sculpted. One such control law results in the 2-4 quadrant hysteresis curve in Fig. 13. This device is beneficial in structural control as energy is removed from the system without an increase in base shear, as seen in Fig. 14. Energy is removed from the system without an increase in the base shear, as shown by the fattening of the combined loop over the structure only loop. This analysis included 5\% of critical damping and $50 \%$ additional stiffness provided by the resetable device incorporating the $2-4$ control law. The structure's natural period is $1.4 \mathrm{~s}$ and the ground motion is the 1995 Kobe record, with full details in [12].

\section{Pressurized Augment Force Devices}

The devices presented to this point have significant advantages in modulating hysteretic behavior that can be considered to be at least initially validated both analytically and experimentally. However, they have a primary limitation in using air as the working fluid. Specifically, the bulk modulus of air is quite low, and thus, the forces generated for a given volume of device are relatively low as compared to hydraulic and other systems. This section augments the force capacity of these validated devices
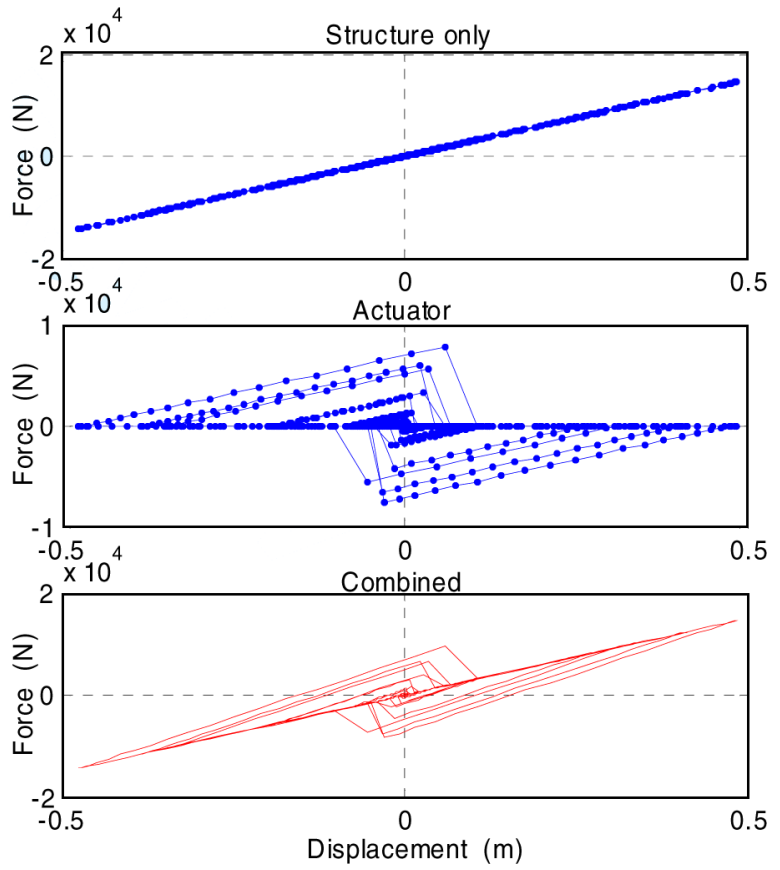

Fig. 14. Hysteresis loops for the uncontrolled structure, semiactive actuator, and the combination.

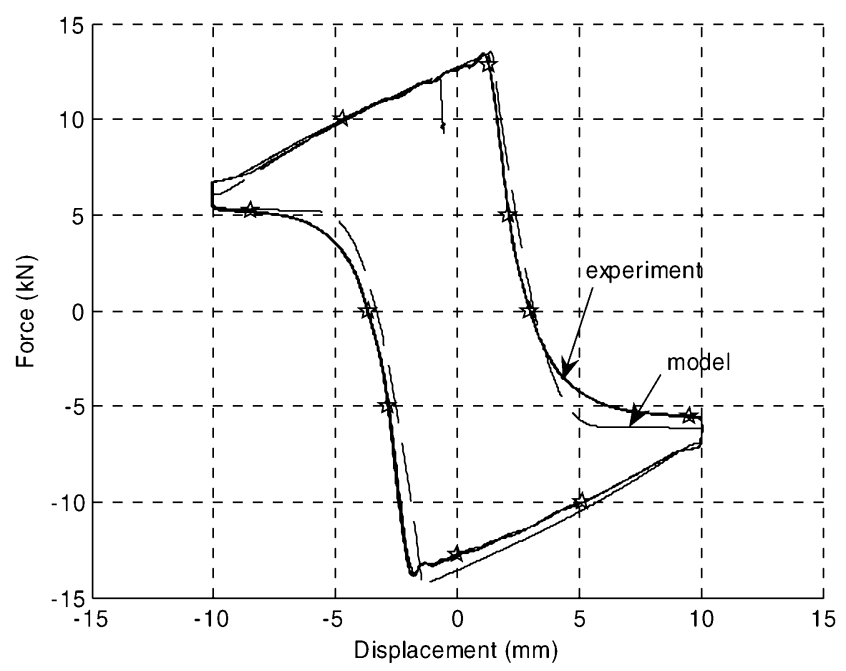

Fig. 15. Experimental results and model prediction at $5 \mathrm{~atm}$ of additional pressure at a frequency of $0.5 \mathrm{~Hz}$.

while maintaining the advantages of using air as the working fluid with the atmosphere as the reservoir.

Specifically, the devices are attached via a second set of controllable valves to a pressurized air source or pressurized input reservoir. Hence, the active chamber of the device can be pressurized to up to six times atmospheric. In actual implementation, these systems could be arranged using stored, pressurized air bottles. The venting valves are as shown in Fig. 6, leading to air. Hence, for an additional minor control input cost, separating input, and outlet valve control, significant force increases can be made.

Fig. 15 shows the results for a 2-4 device with 4 atm of pressure applied as compared to model outputs, providing some 


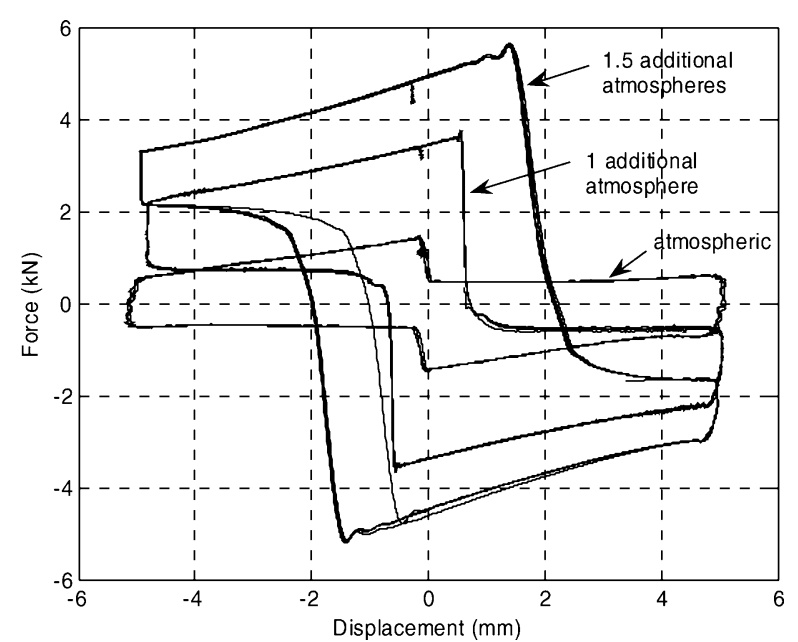

Fig. 16. Result of high-pressure air supply charging the active chamber. Increasing the initial pressure results in a significant increase in the maximum force produced. Tests were run to $5 \mathrm{~mm}$ of amplitude and at a frequency of $0.5 \mathrm{~Hz}$ in each case.

further model validation. Note that this model was augmented to account for the valve size and flow rates that produce lag in response. Hence, it also accounts for sensor and actuator/valve lag as well [16]. Overall, the model accurately predicts the device response, including the energy release rate.

More importantly, the high-pressure air source had the desired effect of increasing the maximum forces produced by the device as compared to forces produced when working from atmospheric pressure. In general, the addition of an atmosphere of pressure to the supply, or initial pressure in the active chamber, more than doubles the maximum force produced by the device. Fig. 16 shows a comparison of the device under 2-4 control working from atmospheric pressure, and with an additional 1 and 1.5 atm of pressure. The maximum force increases from approximately $1.5 \mathrm{kN}$ for the atmospheric supply pressure case to 3.5 and $5.6 \mathrm{kN}$ for the high-pressure source cases, respectively.

There are some specific limitations or potential limitations that should be noted. In particular, this model uses the ideal gas law for the pneumatic prototypes analyzed. However, for hydraulic working fluids, similar equations with equal utility for design and analysis are available. The impact of friction and valve size also interact with piston velocity to affect the results seen in Figs. 8-13 and Figs. 15 and 16 in different ways depending on velocity. Thus, the more detailed models of [15], [16] are required to fully capture these effects. A full analysis and development of that model can also be found in the work of Mulligan [17] for the reader requiring full details on design and analysis that are not in the scope of this paper.

Finally, Figs. 10-13 and Figs. 15 and 16 show experimental results at lower frequencies and velocities. These figures are shown to best illustrate the device capability. As noted, higher frequencies and different valve sizes play a role in the resulting device hysteresis loops, but a role that is managed by design specifics. In this structural control example, frequencies of $1-4 \mathrm{~Hz}$ are of interest. Hence, for clarity, higher frequency results are not shown here, but can be found in detail in [10], [15]-[17].

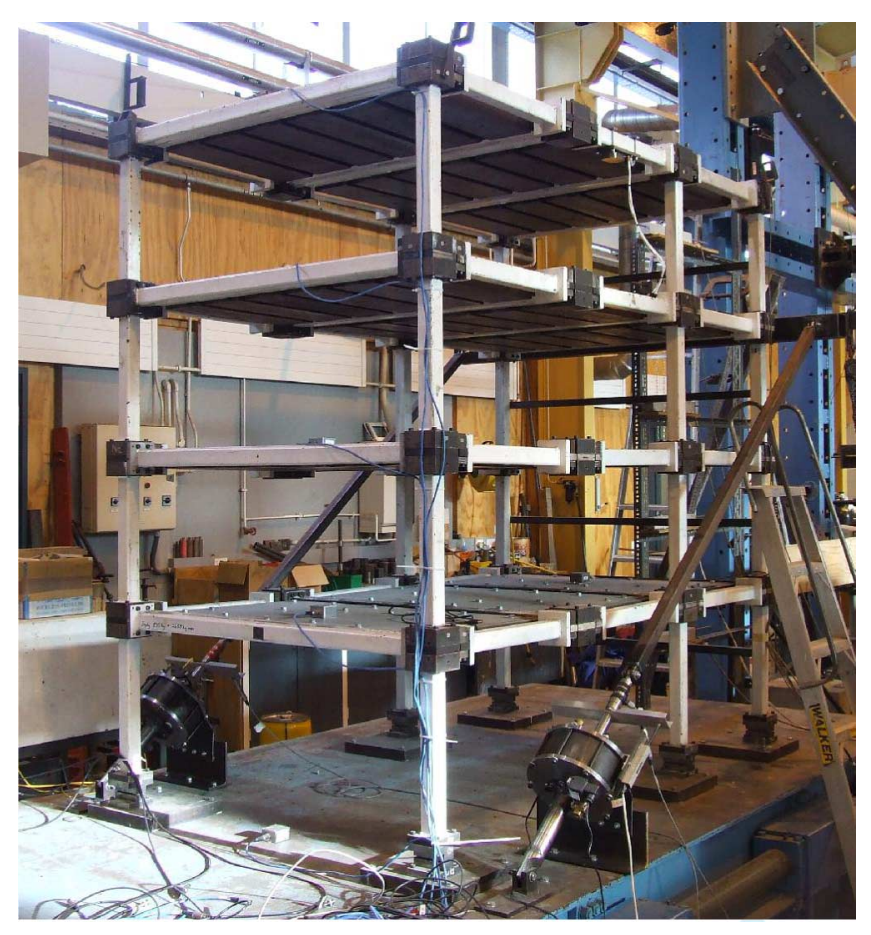

Fig. 17. Four-story structural control shake table experiment with devices on both sides of the structure connected via rigid tendons.

\section{Shake Table Validation}

The devices were finally validated on shake table testing with results as compared to those from design spectra analysis [10]. These tests were done on a one-fifth scale, five-tonne experimental shown in Fig. 17 with a close up of the controlled device with sensor in Fig. 18.

The structure had one device on each side and was subjected to several ground motion intensities for the El Centro, Kobe, and Taft earthquakes. Structural story displacements were measured to determine whether the devices provided a significant reduction in base shear, as shown schematically in Fig. 1. Additionally, the results were analyzed to determine whether the response of the structure matched initial spectral analyzes for response reductions presented in the development of design equations by [10].

The system was servo controlled with a sampling and control rate of $10 \mathrm{kHz}$ for sampling and $1 \mathrm{kHz}$ for control, respectively. All signals were bandpass filtered from 0.1 to $10.0 \mathrm{~Hz}$ to eliminate electronic and sensor noise. Digital accelerometers and capacitive extensometers were both used to measure story motion with similar sampling rates and filtering as required. The dSpace system was used for all control and data capture capabilities in this experiment, including running the shake table displacement input controller. Figs. 19 and 20 show the primary results.

Fig. 19 shows the reductions in base shear promised by Fig. 1 and the prior results in this paper. Specifically, the 27 ground motions are classified via intensity (spectral displacement magnitude SDm), and the calculated base shear is plotted on the $y$ axis. The results are shown for the valves open (friction damper) 


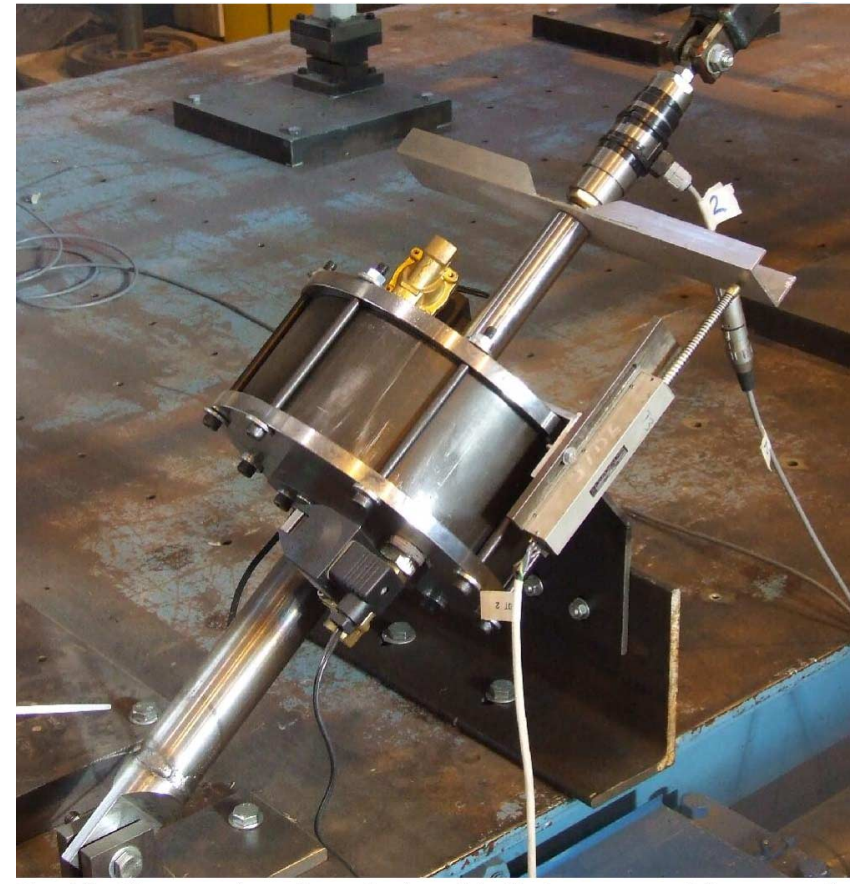

Fig. 18. Closeup view of one device with displacement and force transducers and valve control wiring shown. The displacement sensor is parallel to the device and the force transducer is on the shaft.

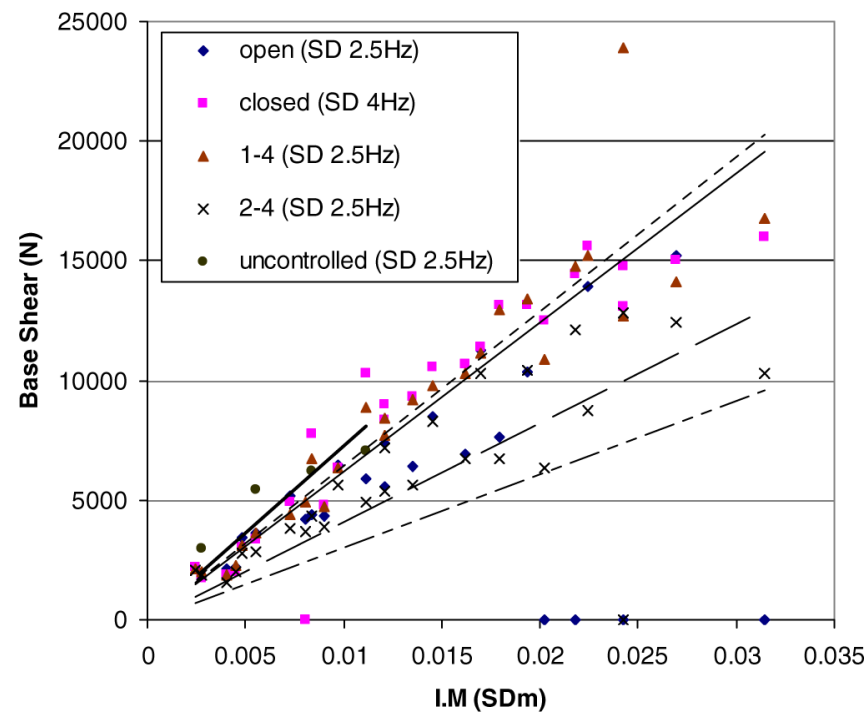

Fig. 19. Base shear in experimental cases versus intensity measure of the ground motion.

case, the valves closed (fail safe) case, the 1-4 device control case, and the 2-4 case. The uncontrolled case is shown for selected ground motions that would not cause large magnitude yielding. A clearly linear behavior, as expected for this structure and these ground motions, is observed.

More importantly, note that the base shear for 2-4 control is lower than that for the uncontrolled and valves-closed cases. Similarly, the 1-4 control shows similar to slightly increased base shear per the results of [10] for this level of ground motion. Hence, the 2-4 devices are able to reduce base shear as promised.
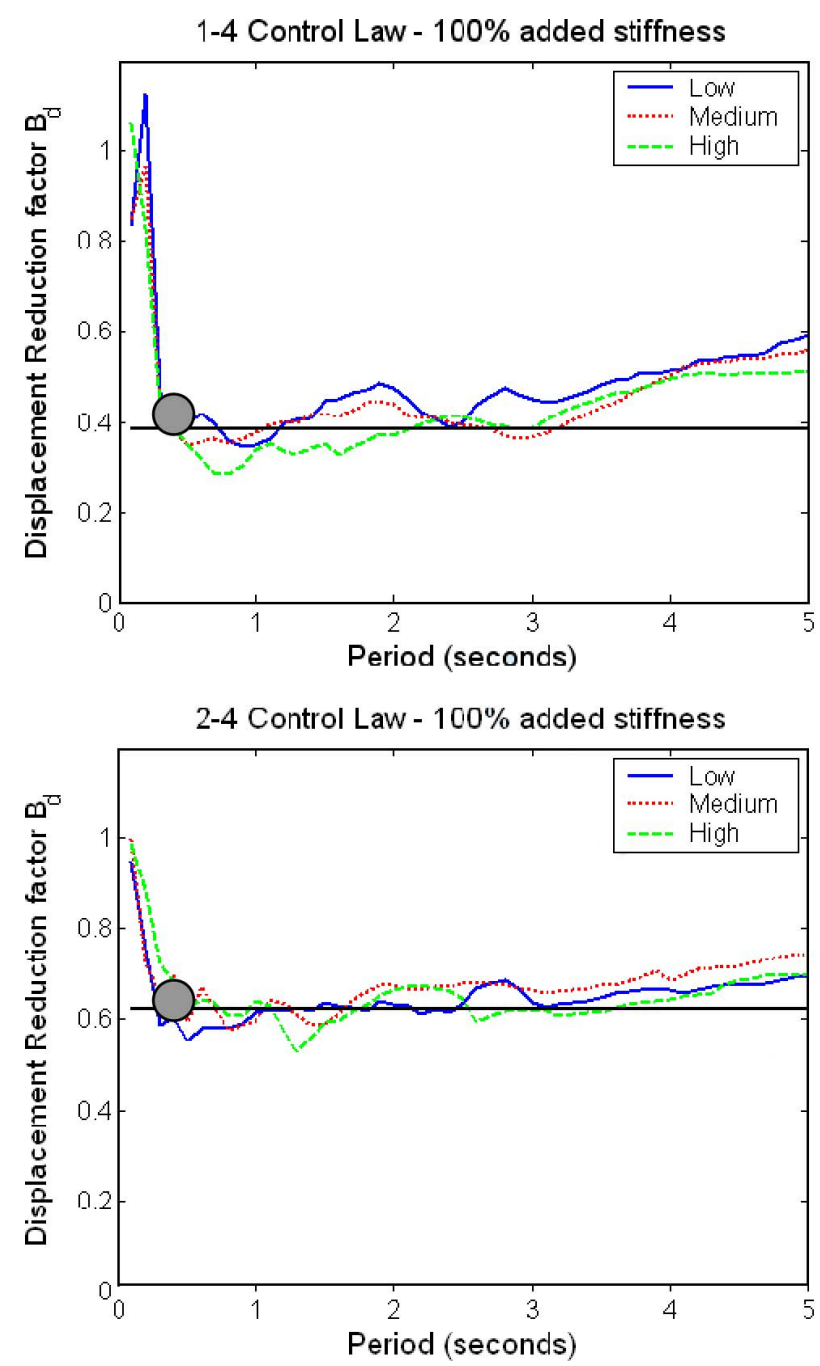

Fig. 20. Response reductions versus spectral analyzes for $1-4$ and $2-4$ devices. The large dot at $T=0.4 \mathrm{~s}$ shows the experimental result overlaid on this figure with the approximately $5 \%$ (absolute) error found in the results comparison.

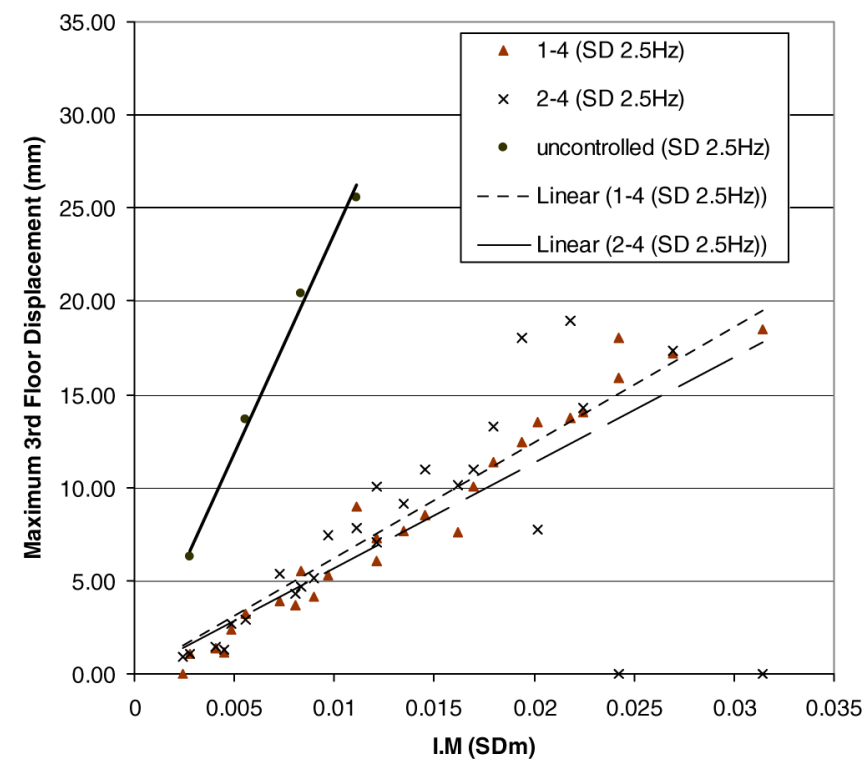

Fig. 21. Response reductions versus spectral analyzes for $1-4$ and 2-4 systems versus the uncontrolled case. 
d

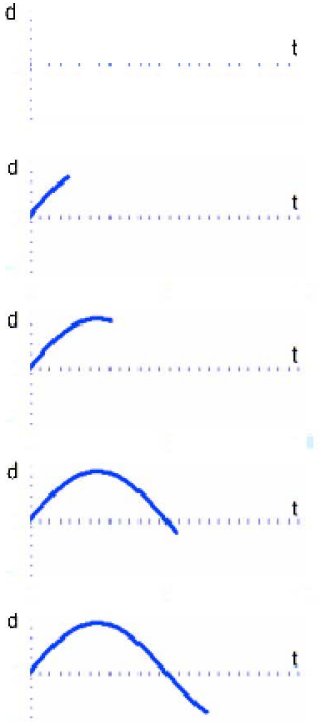

d

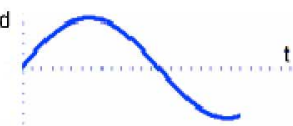

d

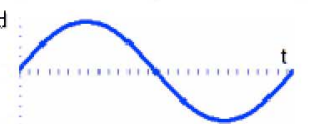

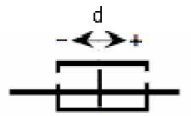
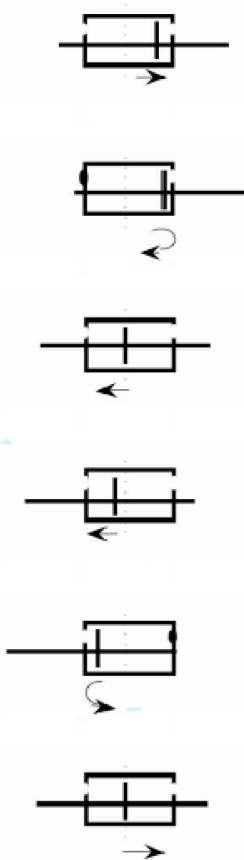
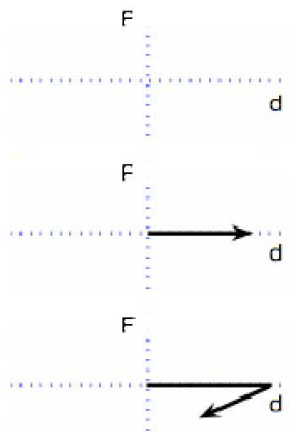

$\mathrm{F}$

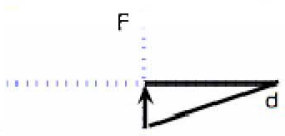

F
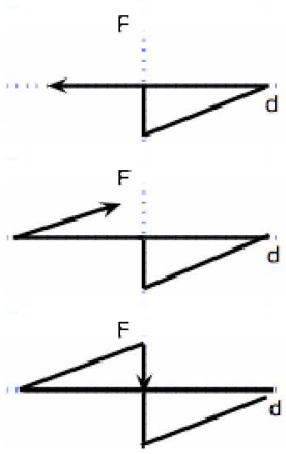

Reset has just occured so chamber pressure is at equilibrium. Hence, the force is zero.

Piston is moving away from zero, motion is unres isted so both valves are held open.

Piston reaches maximum displacement and moves back in the ather direction. Piston is moving towards zero so motion is resisted. Hence, the valve the piston is moving towards is closed.

Piston passes through zero and begins to move away from zero. Hence. the valve is opened releasing the energy and returning the force to zero.

Piston is moving away from zero Both valves are open as motion is unresisted.

Piston reaches maximum displarement and moves back in the ather direction. Piston is moving towards zero so motion is resisted. Hence, the valve the piston is moving towards is closer.

Piston passes zero. The valye is opened releasing the stored energy, returning the force to zero.

Fig. 22. Valve and device control for a 2-4 controlled resetable device to achieve the desired device hysteresis loop.

Fig. 20 shows the results for displacement response as compared to the spectral analysis in [10] for a similar structural period. The displacement response spectra are the linear single degree of freedom design response expected for earthquakes of this magnitude or intensity. The reduction factors shown are versus an unmodified, uncontrolled case. The large dot at period $T=0.4 \mathrm{~s}$ corresponds to the cases and analyzes shown here, using the full-scale El Centro ground motion displacement reduction for the 2-4 and 1-4 cases, as this record matches the spectral analyzes in intensity and probability of occurrence.

More importantly, the third floor peak displacement response reductions seen in the experiments match those from spectral analysis for similarly scaled ground motions to within 5\%. In addition, they show, in Fig. 19, the same levels of impact on base shear forces. In particular, of the 37 experimental results and ignoring extreme outliers, the average reduction factor ranged from 0.38 to 0.45 for the $1-4$ control law of Fig. 20 and was similarly tight for the 2-4 control case. Thus, the results match initial analytical model predictions from [10] based on simplified linear spectral analyzes. Overall, these results help to further validate the fundamental concept of these semiactive control devices, their ability to reshape hysteresis, and their impact on overall structural response in a more complex experimental case.

Similar reductions for all levels of force-displacement response were seen for all 27 ground motions studied. These results are shown in Fig. 21, which captures the peak third story displacement versus ground motion intensity measure. The main point of note in these responses is that the controlled responses are much lower than those for the uncontrolled cases, even if it is merely fail-safe or open valve damping cases. More specifically, note that the $2-4$ cases trend line is approximately $10 \%$ higher than the 1-4 trend line with several wider outliers. These results indicate the lesser overall impact on peak displacement for the 2-4 devices versus the 1-4 devices, particularly at higher intensity measures similar to those studied in [10]. The valves open and closed cases lay in between these cases and the uncontrolled response.

\section{CONCLUSION}

This paper presents the design, analysis, modeling, and validation of semiactive control devices for application to civil infrastructure. The devices are modeled and analyzed in first principles, and then, the overall design approach and tradeoffs are presented. From this beginning, the devices are validated in three separate fashions with increasing realism to the final potential application. Specifically: 1) device validation versus simple first principles models; 2) hybrid (hardware-in-loop) testing with a computer model for the structure showing the capability to reduce response and further validate the device dynamics for realistic ground motions; and 3) large-scale shake table testing with a physical structure at one-fifth full scale in size and full-scale ground motions. In addition, a more detailed model is developed and validated using advanced or augmented devices. These devices use pressurized reservoirs that are actively controlled to augment the force and thus improve the force to 
volume ratio for these devices. As a result, forces are increased by up to six times, and the more detailed design model is validated by errors of less than 5\%-7\% in measured hysteresis loops done in sinusoidal device testing.

All results presented show the basic capability to sculpt the overall hysteretic response of a large- or full-scale structure. These devices are enabled by simple mechatronics and control systems, utilizing simple off the shelf components. Hence, the overall conclusion of this paper is that there are several possible ways to take mechatronics and simple control applications to great effect in mitigating seismic response without requiring large scale forces or power.

A recent work [18] reported a self-optimizing control system for hard rock percussive grilling. The control system superimposes an oscillating force signal onto the drill feed force and demodulates the signal from the drill rotational torque. Along the similar direction, we are applying the modeling and simulation results reported here for the implementation of intelligent structure design and control. The algorithm development will be reported in a separate paper in the future.

\section{APPENDIX}

See Fig. 22 shown at the top of the previous page.

\section{REFERENCES}

[1] J. E. Bobrow, F. Jabbari, and K. Thai, "A new approach to shock isolation and vibration suppression using a resetable actuator," ASME Trans. Dyn. Syst., Meas. Control, vol. 122, no. 3, pp. 570-573, 2000.

[2] L. R. Barroso, J. G. Chase, and S. J. Hunt, "Resetable smart-dampers for multi-level seismic hazard mitigation of steel moment frames," J. Struct. Control, vol. 10, no. 1, pp. 41-58, 2003.

[3] L. M. Jansen and S. J. Dyke, "Semiactive control strategies for MR dampers: comparative study," ASCE J. Eng. Mech., vol. 126, no. 8, pp. 795-803, 2000.

[4] O. Yoshida and S. J. Dyke, "Seismic control of a nonlinear benchmark building using smart dampers," ASCE J. Eng. Mech., vol. 130, no. 4, pp. 386-392, 2004.

[5] Y. Li and C. D. Rahn, "Adaptive vibration isolation for axially moving beams," IEEE/ASME Trans. Mechatronics, vol. 5, no. 4, pp. 419-428, Dec. 2000.

[6] A. C. Pil and H. H. Asada, "Integrated structure/control design of mechatronic systems using a recursive experimental optimization method," IEEE/ASME Trans. Mechatronics, vol. 1, no. 3, pp. 191-203, Sep. 1996.

[7] S. J. Dyke and B. F. Spencer, "Modelling and control of magnetorheological dampers for seismic response reduction," Smart Mater. Struct., vol. 5, no. 5, pp. 565-575, 1996.

[8] B. F. Spencer, S. J. Dyke, M. K. Sain, and J. Carlson, "Phenomenological model for magneto-rheological dampers," ASCE J. Eng. Mech., vol. 123, pp. 230-238, 1997.

[9] F. Jabbari and J. E. Bobrow, "Vibration suppression with a resetable device," ASCE J. Eng. Mech., vol. 128, no. 9, pp. 916-924, 2002.

[10] G. W. Rodgers, J. B. Mander, J. G. Chase, K. J. Mulligan, B. L. Deam, and A. J. Carr, "Re-shaping hysteretic behaviour-Spectral analysis and design equations for semi-active structures," Earthq. Eng. Struct. Dyn. (EESD), vol. 36, no. 1, pp. 77-100, 2007.

[11] K. J. Mulligan, J. G. Chase, A. Gue, T. Alnot, G. W. Rodgers, J. B. Mander, R. E. Elliott, B. L. Deam, L. Cleeve, and D. Heaton, "Large scale resetable devices for multi-level seismic hazard mitigation of structures," in Proc. 9th Int. Conf. Struct. Safety Rel. (ICOSSAR), Rome, Italy, Jun. 19-22, 2005, CD-ROM.

[12] J. G. Chase, K. J. Mulligan, A. Gue, T. Alnot, G. W. Rodgers, J. B. Mander, R. B. Elliott, B. L. Deam, L. Cleeve, and D. Heaton, "Re-shaping hysteretic behaviour using semi-active resetable device dampers," Eng. Struct., vol. 28, no. 10, pp. 1418-1429, 2006.
[13] G. C. Kao, "Design and shacking table tests of a four-storey miniature structure built with replaceable plastic hinges," Masters thesis, Civil Eng., Univ. Canterbury, Christchurch, New Zealand, 1998.

[14] S. Hunt, J. G. Chase, and L. R. Barroso, "The impact of time varying equilibrium location in the semi-active control of non-linear seismically excited structures," in Proc. 7th Int. Conf. Control, Autom., Robot. Vis., Singapore, 2002, pp. 892-897.

[15] K. J. Mulligan, J. G. Chase, R. B. Elliott, B. Horn, B. L. Deam, J. B. Mander, and G. Danton, "Simple, robust hybrid test systems for non-linear structural dynamic research and development," in Proc. 19th Australasian Conf. Mech. Struct. Mater. (ACMSM), Christchurch, New Zealand, 2006, pp. 331-336.

[16] K. J. Mulligan, J. G. Chase, J. B. Mander, and R. B. Elliott, "Semi-active resetable actuators incorporating a high pressure source," in Proc. New Zealand Soc. Earthq. Eng. 2007 Conf. (NZSEE 2007), Palmerston North, New Zealand, Mar. 30-Apr. 1, CD-ROM.

[17] K. J. Mulligan, "Experimental and analytical studies of semi-active and passive structural control of buildings," Ph.D. thesis, Dept. Mech. Eng., Univ. Canterbury, Christchurch, New Zealand, 2007.

[18] G. L. Cavanough, M. Kochanek, J. B. Cunningham, and I. D. Gipps, "A self-optimizing control system for hard rock percussive drilling," IEEE/ASME Trans. Mechatronics, vol. 13, no. 2, pp. 153-157, Apr. 2008.

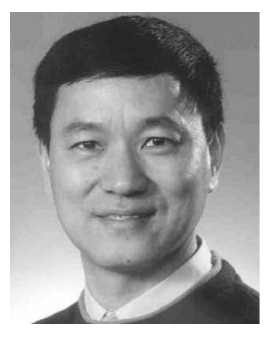

XiaoQi Chen (M'03-SM'07) received the B.E. degree in mechanical engineering from South China University of Technology, Guangzhou, China, in 1984, the M.Sc. degree from the Department of Materials Technology, Brunel University, London, U.K., in 1986, and the Ph.D. degree from the Department of Electrical Engineering and Electronics, University of Liverpool, Liverpool, U.K., in 1989.

$\mathrm{He}$ is currently an Associate Professor and the Director for Mechatronics Engineering Program at the University of Canterbury, Christchurch, New Zealand. His current research interests include robotics, mechatronic systems, and manufacturing automation.

Dr .Chen was a recipient of the China-U.K. Technical Co-Operation Award. $\mathrm{He}$ is a Senior Member of the Society of Manufacturing Engineers (SME).

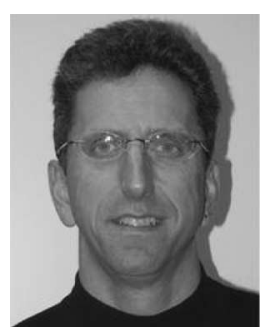

J. Geoffrey Chase received the B.S. degree in mechanical engineering from Case Western Reserve University, Cleveland, OH, in 1986, and the M.S. degree in mechanical engineering and the Ph.D. degree in civil engineering from Stanford University, Palo Alto, CA, in 1991 and 1996, respectively.

$\mathrm{He}$ is currently a Professor in the Department of Mechanical Engineering and the Center for BioEngineering, University of Canterbury, Christchurch, New Zealand, and an Honorary Clinical Senior Lecturer at the University of Otago, Christchurch School of Medicine, Christchurch. His current research interests include novel modelbased control systems and their implementation in the broad areas of structural engineering and biomedical/clinical engineering.

Kerry J. Mulligan received the B.E. and Ph.D. degrees in mechanical engineering in 2003 and 2007, respectively, both from the University of Canterbury, Christchurch, New Zealand.

Her current research interests include dynamic control of structures and realtime, virtual-real integrated test systems. 


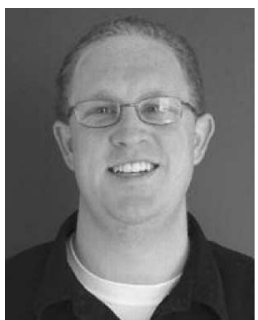

control.
Geoffrey W. Rodgers received the B.E. (Honors) degree in mechanical engineering in 2006 from the University of Canterbury, Christchurch, New Zealand, where he is currently working toward the Ph.D. degree.

He is a NZ MacDiarmid Award Researcher and a Fulbright Award Grantee attending Texas A\&M University as part of his research. His current research interests include passive and semiactive control of structures to mitigate seismic response, as part of broader interests in dynamic systems modeling and

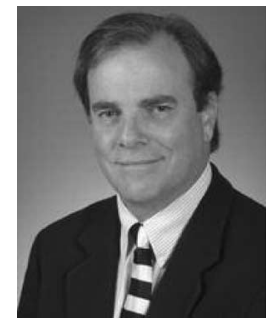

John B. Mander received the B.E. (Honors) and $\mathrm{Ph} . \mathrm{D}$. degrees in civil engineering from the University of Canterbury, Christchurch, New Zealand, in 1979 and 1984, respectively.

Since that time, he has held various positions in professional practice and academia in both the United States and New Zealand. Since 2007, he has been the inaugural holder of the Zachry Professorship in Design and Construction Integration in the Zachry Department of Civil Engineering, Texas A\&M University. His current research interests include developing new methods of design, construction, vibration control, and loss estimation of bridge and building structures. 